\title{
Child-Pugh Class C11
}

National Cancer Institute

\section{Source}

National Cancer Institute. Child-Pugh Class C11. NCI Thesaurus. Code C146796.

A total score of 11 for hepatic function, corresponding to class $C$ in the Child-Pugh classification. 